\title{
Sentidos e Processos Psicossociais envolvidos na Inclusão pelo Trabalho na Saúde Mental
}

\author{
Ramiz Candeloro Pedroso de Moraes \\ Centro Universitário UNIFAFIBE. SP, Brasil.
}

\author{
Carlos Roberto de Castro-Silva \\ Universidade Federal de São Paulo, SP, Brasil.
}

Resumo: As mudanças teóricas, políticas e sociais no campo da reabilitação psicossocial têm trazido novas possibilidades de investigação da prática. Neste artigo, investigamos os processos psicossociais que influenciam no trabalho solidário dos sujeitos da Saúde Mental, enfatizando cotidiano e sentidos. O método que utilizamos é orientado pela concepção de mundo da Psicologia Sócio-histórica, sendo uma pesquisa de epistemologia qualitativa. Realizamos um estudo de caso com inspiração etnográfica, por meio de entrevistas e observações participantes em uma cooperativa de reciclagem em Santos, Brasil. Os sujeitos entrevistados foram seis homens e quatro mulheres e, do total, oito são usuários dos serviços de Saúde Mental e dois são técnicos. A maioria tem mais de 50 anos, não completou o ensino fundamental e trabalha na cooperativa há mais de três anos. A análise pela Hermenêutica de Profundidade resultou que, entre complexas relações institucionais, os cooperados trazem sentidos positivos ao trabalho, seja pelo afeto, pelo retorno financeiro ou pelas reconfigurações familiares e sociais. Estas novas formas de sociabilidade vêm destruindo as barreiras da dialética exclusão/inclusão social e desmistificando o preconceito com o louco e o pobre. A não competição, aliada à participação social e uma cultura solidária, tende a potencializar estes projetos e seus sujeitos.

Palavras-chave: Saúde Mental, Trabalho, Inclusão Social, Economia Solidária.

\section{Senses and Psychosocial Processes involved in the Work of Social Inclusion in Mental Health}

\begin{abstract}
The theoretical, political and social changes in the field of psychosocial rehabilitation, have brought new possibilities for practical research. In this article we investigate the psychosocial processes that influence the solidarity work of the subjects of Mental Health, emphasizing everyday life and senses. The method we use is guided by the conception of the world of Socio-Historical Psychology, in a qualitative epistemology research. We conducted a case study with ethnographic inspiration, through interviews and participant observation in a recycling cooperative in Santos, Brazil. The interviewees were six men and four women: eight of them were users of mental health services and two were technicians. Most of them were more than 50 years, had not completed elementary school and had worked in the cooperative for more than three years. The analysis by Depth Hermeneutics, which resulted from complex institutional relations, showed that the cooperative members bring positive senses to work, whether through affection, financial return or family and social reconfigurations. These new forms of sociability are destroying the barriers of dialectical social exclusion/inclusion and demystifying the prejudice against the ill and the poor. Absence of competition, combined with social participation and a supportive culture, tend to potentiate these projects and their subjects.
\end{abstract}

Keywords: Mental Health, Labour, Social Inclusion, Solidary Economic. 


\title{
Sentidos y Procesos Psicosociales involucrado en Inclusión a través de Trabajo en Salud Mental
}

\begin{abstract}
Resumen: Los cambios teóricos, políticos y sociales en el campo de la rehabilitación psicosocial han traído nuevas posibilidades para la investigación práctica. En este artículo se investigan los procesos psicosociales que influyen en el trabajo solidario de los sujetos de Salud Mental, con énfasis en lo cotidiano y los sentidos. El método que utilizamos se guía por la concepción de mundo de la Psicología Socio-Histórico, en una investigación de epistemología cualitativa. Hemos realizado un estudio de caso con inspiración etnográfica, a través de entrevistas y observación participante en una cooperativa de reciclaje en Santos, Brasil. Los entrevistados fueron seis hombres y cuatro mujeres: ocho usuarios de servicios de salud mental, y dos técnicos. La mayoría tiene más de 50 años, no ha terminado la escuela primaria y ha trabajado en la cooperativa por más de tres años. Según el análisis por Profundidad Hermenéutica, resultado de relaciones institucionales complejas, las personas de esta cooperativa aportan sensibilidad positiva al trabajo, ya sea a través del afecto, el retorno financiero o las reconfiguraciones familiares y sociales. Estas nuevas formas de sociabilidad están destruyendo las barreras de la dialéctica exclusión/inclusión social y desmitificando el prejuicio contra la locura y la pobreza. La ausencia de competencia, combinada con participación social y una cultura de solidaridad, tienden a generar el fortalecimiento de estos proyectos y sus sujetos.
\end{abstract}

Plabras clave: Salud Mental, Trabajo, Inclusión social, Economía Solidaria.

\section{Introdução}

Partindo da perspectiva materialista histórica e dialética, entendemos que o 'trabalho' é ontológico ao ser humano e central na vida das pessoas que não existiriam sem ele, porque seriam apenas animais. Ainda que alienado, o trabalho se faz presente em toda a história da humanidade e promove a dialética homem-meio e o desenvolvimento da sociabilidade, sendo categoria central na compreensão do homem como ser social (Salgueiro, 2013).

No campo das políticas públicas brasileiras de Saúde Mental, a inclusão social pelo trabalho para os usuários destes serviços é inspirada na Reforma Psiquiátrica italiana, por meio da atitude estratégica da Reabilitação Psicossocial do italiano Saraceno (1999). Para o autor, esta tem um 'evidenciador' particularmente iluminado da principal característica da psiquiatria" (p. 16), o entretenimento, que significa ter dentro, passar prazerosamente o tempo. A pessoa trancada em um hospital psiquiátrico ficava (e fica) esperando a cura da doença ou a própria morte. Saraceno faz uma crítica a esta questão e também à Psiquiatria, colocando em xeque este modelo. $\mathrm{O}$ autor propõe que os pacientes devem ser cuidados em contextos abertos, de base comunitária e familiar, sendo importante as motivações, as expectativas do cuidador, bem como a afetividade e a materialidade da assistência no desenvolvimento efetivo das propostas de vida construídas com os pacientes. Para o autor, a Psiquiatria não critica a própria impotência, deixando de individualizar o tratamento, o que permitiria a melhora do paciente. Com isso, optam por tratamentos clínicos biopsicomédicos, enclausuradores e deixam de atentar a "(...) elementos suficientemente mais decisivos para a evolução do paciente” (Saraceno, 1999, p. 17).

O redirecionamento na forma de tratar o paciente psiquiátrico centraliza a questão da cidadania, que “[...] não é a simples restituição de seus direitos formais, mas a construção de seus direitos substanciais, e é dentro de tal construção (afetiva, relacional, material, habitacional, produtiva) que se encontra a única Reabilitação possível” (Saraceno, 1999, p. 18).

A mudança brusca no campo da Reabilitação Psicossocial pela lógica da desinstitucionalização coloca novos modos de pensar a inclusão social pelo trabalho que promova o sujeito e, para tanto, há a necessidade de se colocá-la em prática por meio da construção de 'espaços reais' (Nicácio, \& Kinker, 1997; Nicácio, Mangia, \& Ghirardi, 2005). Estes são pautados na Economia Soli- 
dária ${ }^{1}$ e se organizam em cooperativas sociais, oficinas de geração de renda, lojas sociais, feiras de troca e de venda do material produzido. Com isto, esta 'outra economia' está interessada no desenvolvimento do ser humano em detrimento do lucro (Singer, 2002).

No Brasil, Andrade, Burali, Vida, Fransozio e Santos (2013) realizaram uma análise no Banco de Dados do Portal da Rede de Empreendimentos de Saúde Mental e Economia Solidária e no CIST - Cadastro de Iniciativas de Inclusão Social pelo Trabalho, locais onde são mapeados os empreendimentos. Nesta análise, constataram que há muita diversidade nos produtos e serviços oferecidos, mas predominam o artesanato, a coleta seletiva/reciclagem, a confecção de alimentos, a tecelagem e a marcenaria. Apesar de estarem instaladas em todo o Brasil, a predominância destas atividades é na Região Sudeste, sua organização mais comum é por meio de oficinas e os locais mais utilizados são os próprios Centros de Atenção Psicossocial (CAPS). Os produtos geralmente são comercializados tanto no próprio CAPS, quanto em feiras pela região e os usuários dos serviços de saúde mental são acompanhados por profissionais das equipes de saúde.

Um estudo de revisão bibliográfica realizado em bases nacionais e internacionais constatou que, nos países europeus e norte-americanos, utiliza-se o termo reabilitação vocacional para designar a promoção do retorno dos usuários dos serviços de saúde mental ao mercado de trabalho. Nestes países, os artigos se referem à pessoa sempre no âmbito da doença e a inclusão se dando por meio da recolocação no mercado de trabalho. Já no Brasil, a pessoa é considerada sujeito em potencial das ações de reabilitação psicossocial e a inclusão se dá por meio do cooperativismo e da Economia Solidária. Assim, os autores concluem que é necessário que a reabilitação psicossocial destas pessoas com dependência química e/ou transtorno mental seja pautada pelo trabalho emancipatório e não da maneira que segue uma lógica adaptativa de recolocação em empresas: "Caso contrário, corre-se o risco de que o trabalho contribua para produzir ou agravar estados de adoecimento, em oposição ao desejado propósito de promoção de saúde" (Bonadio, \& Silveira, 2013, p. 107).
Podemos refletir que a reabilitação vocacional está ideologicamente ligada à inclusão perversa (Sawaia, 2011a) pelo mercado capitalista. Isto significa que o que importa é incluir um número maior pessoas, independentemente de elas estarem felizes e de se isto produz saúde. Já na inclusão pela Economia Solidária em nosso país, há uma perspectiva humana de potencialização do trabalho e dos seres humanos envolvidos neste processo. Mas como será o cotidiano destes projetos? Eles efetivamente geram inclusão social, autonomia e cidadania para estas pessoas?

Entendemos que, neste contexto, é importante ouvir e reinterpretar (Thompson, 2011) a experiência daqueles que vivenciam este processo "na pele", bem como os processos psicossociais, ou seja, as influências históricas, materiais, contextuais, culturais, intersubjetivas, afetivas e ético-políticas do cotidiano de trabalho. Desta forma, mais do que expor um estudo de caso, pretendemos discutir os avanços e os impasses deste tema tão recente e complexo, que afeta diretamente a vida de milhares de pessoas no Brasil e no mundo.

O objetivo deste artigo é investigar os processos psicossociais que influenciam no trabalho solidário dos usuários dos serviços de saúde mental, enfatizando o cotidiano e os sentidos atribuídos.

\section{Método}

A pesquisa seguiu a metodologia qualitativa, inspirada na visão de mundo da Psicologia Sócio-histórica, que traz para a Psicologia o materialismo histórico e dialético de Karl Marx (1818-1883). Portanto, estudamos subjetividades que se constituem simultaneamente elementos concretos, sociais e históricos, marcando a singularidade da vida das pessoas (González-Rey, 2011).

O local estudado foi uma cooperativa de reciclagem composta por usuários dos serviços de saúde mental e de assistência social do município de Santos, Brasil. Esta cooperativa está ligada à Seção de Reabilitação Psicossocial - SERP (área técnica de Saúde Mental), que tem como objetivo promover oportunidades de capacitação e inserção profissional dos seus

\footnotetext{
${ }^{1}$ A Economia Solidária é um termo que se refere às práticas organizadas de trabalho, tendo como princípios cooperação e autogestão, comumente encontradas em grupos informais de geração de renda, sistemas de troca, cooperativas de trabalho e associações de consumidores e produtores (Gaiger, 2013). Alguns dos seus principais fundamentos são: solidariedade em detrimento da competição; decisões por meio de assembleias democráticas; repartição dos ganhos e autogestão em detrimento da heterogestão (Singer, 2002).
} 
usuários. Diversas oficinas são oferecidas na SERP: encadernação, mosaico, bijuterias, tricô, jardinagem, pequenos reparos hidráulicos, bazar e pintura de pano de prato, além de centralizar três projetos que compõem a cooperativa estudada: um de cantinas, um de manutenção de praças públicas e um de reciclagem de lixo (foco deste trabalho).

Foi realizado um estudo de caso com inspiração etnográfica. Neste modo de pesquisar, estar no campo de maneira extensiva e não intensiva, registrar tudo e se relacionar bem com as pessoas pesquisadas, torna-se uma tarefa imprescindível ao pesquisador, que deve considerar o contexto sociocultural dos sujeitos e da instituição (Sato, \& Souza, 2001). Estivemos no campo por aproximadamente seis meses entre os anos de 2012 e 2013. As técnicas e instrumentos utilizados nesta pesquisa foram:

a) Análise documental - para compreender a história, as políticas e as relações institucionais que se estabeleciam ali, analisamos documentos disponibilizados pela gestão da cooperativa, como seu Estatuto Social, Regulamento Interno, Cartilha histórica do convite para os usuários dos serviços de saúde mental participarem da cooperativa e convênios institucionais.

b) Observação participante - com o objetivo de compreender o cotidiano, a partir de suas rotinas, seus dilemas e as relações intersubjetivas estabelecidas entre os cooperados, nos colocando no lugar e no contexto social destes (Minayo, 2010; Sato, \& Souza, 2001).

c) Diário de campo - anotações sobre tudo o que se pôde observar no campo, como nossas impressões pessoais e reflexões sobre as observações realizadas (Minayo, 2010).

d) Entrevistas individuais em profundidade - possibilitam apreender na história de vida dos sujeitos e, com uma orientação nas perguntas que enfoquem o objeto do trabalho, a obtenção de uma fonte mais completa para o estudo. Elas foram realizadas com dez pessoas - oito usuários dos serviços de saúde mental que trabalham na cooperativa e dois técnicos que colaboram na gestão. Foram entrevistados seis homens e quatro mulheres (nomes fictícios), sendo que quase todos estão na cooperativa há mais de três anos. A maioria tem mais de 50 anos e não completou o ensino fundamental. As entrevistas seguiram o critério de saturação proposto por Minayo (2010), que pressupõe uma interrupção das entrevistas a partir da percepção do pesquisador sobre seu entendimento da lógica interna do grupo. Os critérios de inclusão dos sujeitos foram: frequentar um dos NAPS (Núcleos de Apoio Psicossocial) ${ }^{2}$ da cidade; participar da cooperativa há mais de um ano e ter mais de dezoito anos. Neste trabalho não foi relevante o diagnóstico psiquiátrico, já que a referência teórica que utilizamos repudia a estigmatização. Os critérios de exclusão: se o sujeito não aceitasse participar voluntariamente da pesquisa; linguagem que impedisse a transcrição e análise da entrevista. Não excluímos nenhum participante da pesquisa. Os técnicos eram apenas dois, um encarregado e uma contadora e trabalhavam na cooperativa há muitos anos.

As análises do material seguiram a orientação da Hermenêutica de Profundidade (HP) (Demo, 2012; Thompson, 2011), dividindo-as em três patamares:

Análise sócio-histórica - orienta o estudo para que não se prenda somente ao estado atual do objeto, mas considerando suas conexões sociais e sua historicidade, ambas relacionados às formas de "produção, circulação e recepção das formas simbólicas" (Thompson, 2011, p. 34).

Análise discursiva-Thompson (2011) explica que são bem-vindos métodos que possam ser colocados e relacionados com a HP. Nós optamos por incluir neste patamar a análise discursiva por meio dos núcleos de significação (Aguiar, \& Ozella, 2006; 2013), um método de apreensão de sentidos subjetivos da Psicologia Sócio-histórica.

Interpretação/reinterpretação - é a reconstrução crítica partir da reinterpretação do que já está pré-interpretado pelos atores do campo. Assim, esta etapa tem o objetivo de reconstruir a informação qualitativa em profundidade, sobretudo de maneira contextualizada, criativa, sintética e crítica, pelo entrelaçamento da análise sócio-histórica e da análise discursiva.

O Projeto foi aprovado pelo CONEP e cumpriu a Resolução no 466/2012 do CNS, informando aos sujeitos todos os passos da pesquisa e eles só participaram da entrevista após assinatura de Termo de Consentimento Livre Esclarecido.

\footnotetext{
${ }^{2}$ A nomenclatura NAPS (Núcleo de Apoio Psicossocial) é utilizada em Santos, Brasil, pela importância que estes equipamentos assumiram historicamente na cidade. Ainda assim, o NAPS tem a mesma configuração do CAPS (Centro de Atenção Psicossocial), definido pela Portaria GM/MS: nº 336, de 19 de fevereiro de 2002 (Brasil, 2002).
} 


\section{Resultados e Discussão}

\section{A sócio-historicidade e o cotidiano da cooperativa em questão}

Nesta primeira discussão, nos referimos à análise sócio-histórica (Demo, 2012; Thompson, 2011), pretendendo localizar, compreender e relacionar aspectos históricos e contextuais sobre a cooperativa estudada.

Com promulgação da Constituição da República Federativa do Brasil em 1988, garantiu-se o direito de todos à saúde e seu dever ao Estado. Assim, em 1990, consolidou-se a Lei Orgânica da Saúde, a Lei n ${ }^{\circ}$ 8.080/90 (Brasil, 1990), dando início ao Sistema Único de Saúde, o SUS. Junto a este período de mudanças, em 1989, acontece a intervenção ao hospital psiquiátrico Casa de Saúde Anchieta em Santos, questão emblemática para a história da Saúde Mental no país. As violências praticadas contra os internos, incluindo mortes, gerou esta intervenção inédita. Kinoshita (2009) explica que intervir em hospitais psiquiátricos é algo recorrente na história, mas, em Santos, o inédito foi que o poder público municipal assumiu a direção do hospital privado e tornou-se responsável pela saúde da população, objetivando sobretudo, o direito dos internados.

Com esta ação e a inspiração italiana de desinstitucionalização, Santos cria uma rede aberta de serviços substitutivos de base comunitária, na qual os pacientes começam a serem ouvidos dentro do sistema. Segundo Kinker (2011), esta rede era composta por: cinco NAPS, o NAT (Núcleo de Apoio ao Toxicodependente), o Centro de convivência TAMTAM, os Centros de Valorização da Criança e a Unidade de Reabilitação Psicossocial - nome dado ao Núcleo de Trabalho quando instituído e que atualmente se chama Seção de Reabilitação Psicossocial-SERP. Nesta Seção, está ligada a cooperativa em questão que foi consolidada no início dos anos 1990, a partir da criação de projetos de trabalho, como o de manutenção de jardins das praças públicas e uma cantina com oficina de cozinha e venda de salgados e doces. Esses projetos também integram a cooperativa estudada, mas o foco do nosso estudo é a reciclagem de lixo que efetivamente gerou e gera renda e possibilidades financeiras para os usuários dos serviços de saúde mental (Kinker, 2011). Atualmente, aproximadamente 26 anos após sua construção, a reciclagem conta com relações institucionais bem consolidadas. Apesar da dificuldade no acesso à informação, conseguimos construir este quebra-cabeça institucional após algum tempo de observações participantes e análise documental. As secretarias municipais de Saúde (área técnica de Saúde Mental) e Assistência social têm o papel de encaminhamentos de pessoas que utilizam seus equipamentos e envio de profissionais para acompanhar os trabalhadores in loco. A secretaria de Meio Ambiente, em parceria com uma empresa mista de planejamento e operadora de serviços públicos, ajuda na gestão do projeto. Pela sua centralidade neste contexto, construímos uma figura para elucidar estas parcerias:

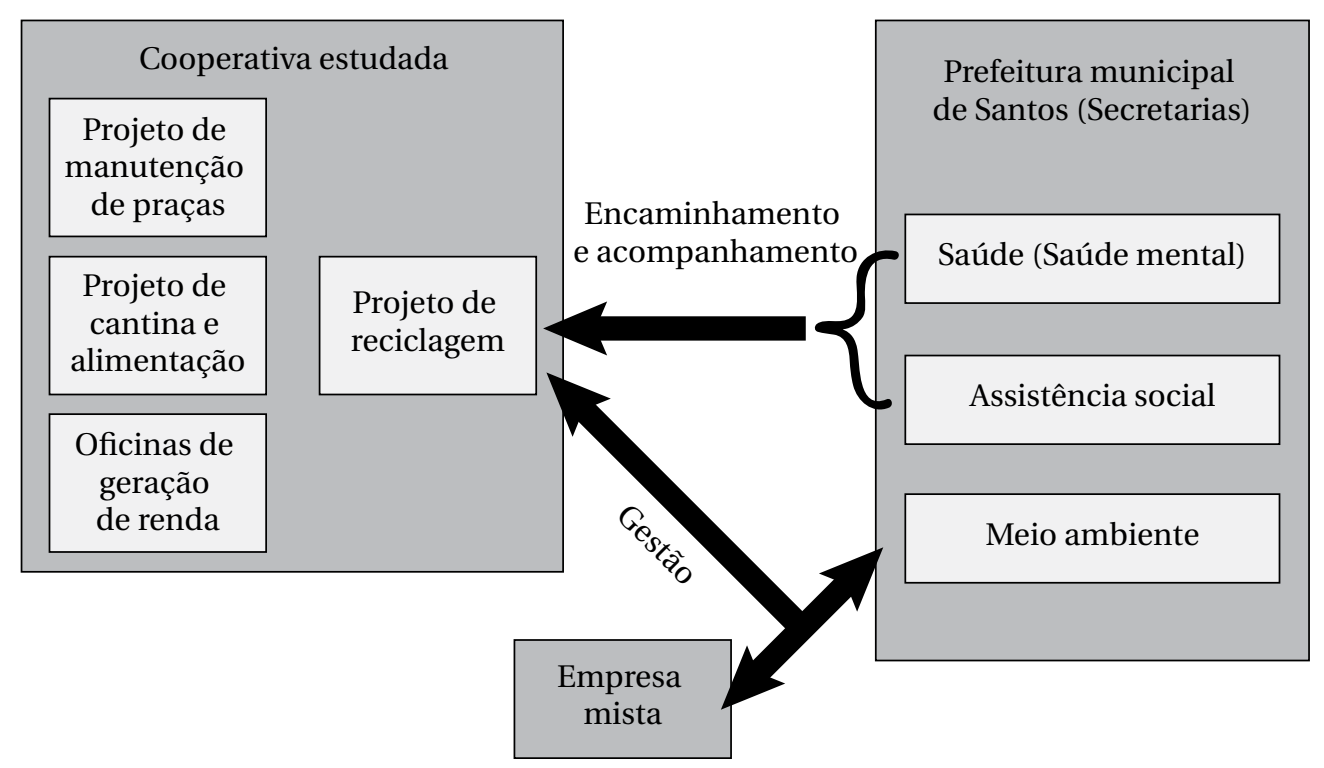

Figura 1

Esquema de relações institucionais. 
Esta estrutura ajuda a cooperativa a se manter viva por tanto tempo no mercado capitalista. Mas a que custo? Consideramos que circulam muitos poderes e hierarquias, mas, em meio a esta situação, qual o lugar dos trabalhadores? Notamos que há uma naturalização destas relações. Martins (2003), baseando-se em Martín-Baró, explica que o poder busca normatizar as ações humanas, agindo de duas maneiras no comportamento humano, "uma imediata, impondo uma direção concreta à ação; outra mediata, configurando o mundo das pessoas e determinando os elementos constitutivos dessa mesma ação" (p. 213). Nestas relações, será possível agir como diz o Estatuto da Cooperativa em seu artigo $2^{\circ}$, parágrafo $6^{\circ}$, "A cooperativa, nos termos da Lei no 5.764/71, efetuará suas operações sem qualquer objetivo de lucro"? Ou ainda, discutir e repensar em assembleia as sobras (aproximadamente equivalente ao lucro da empresa capitalista) e a retirada (equivalente ao salário) (Singer, 2002)?

Neste contexto, investigamos o cotidiano dos trabalhadores por compreender que a vivência no trabalho soma-se à constituição da subjetividade deles. Para Heller (2008),

A vida cotidiana é a vida do homem inteiro; ou seja, o homem participa na vida cotidiana com todos os aspectos de sua individualidade, de sua personalidade. Nela, colocam-se em funcionamento todos os seus sentidos, todas as suas capacidades intelectuais, suas habilidades manipulativas, seus sentimentos, paixões, ideias, ideologias. O fato de que todas as suas capacidades se coloquem em funcionamento determina também, naturalmente, que nenhuma delas possa realizar-se, nem de longe, em toda sua intensidade (p. 31).

Esta definição de Heller sobre o cotidiano evidencia que os trabalhadores não são meros instrumentos no ambiente de trabalho, como também não são dotados de apenas uma característica, como, por exemplo, serem loucos. Esta perspectiva oferece base teórica para refletir sobre a superação do olhar preconceituoso sobre a pessoa com transtorno mental.

Durante as visitas de campo, pudemos observar como são os processos de trabalho dos cooperados. A jornada de trabalho diária dos usuários encaminhados pela Saúde Mental é de seis horas e dos usuários encaminhados pela Assistência Social, de oito horas. Isto se justifica pelo uso do medicamento dos primeiros. Nesta separação encontra-se um dilema, porque alguns eram usuários dos dois serviços e isto gerava um desconforto para aqueles que não conseguiam reduzir a jornada para seis horas.

No período em que realizamos a pesquisa, o número de cooperados era de aproximadamente oitenta, sendo um terço de usuários da Saúde Mental e o restante da Assistência Social. O local que abriga a cooperativa é um galpão aberto, com uma pequena área fechada que abarca a cozinha, os banheiros e o escritório. Nestes locais estavam os postos de trabalho dos cooperados: alguns trabalham na cozinha montando as refeições, outros cuidam da limpeza da área fechada e a maior parte trabalhava no galpão com a reciclagem. É interessante ressaltar que há rotatividade nesta divisão do trabalho, por exemplo, quem trabalha na limpeza um mês, no outro, estará na reciclagem e depois na cozinha.

Além dos cooperados, Jorge (sujeito entrevistado nesta pesquisa), que vai todos os dias, desempenha a função de encarregado, ou seja, aquele que coordena as atividades de reciclagem e treina os novos trabalhadores. No período que estivemos na cooperativa e pelos relatos dos sujeitos, ele não agia como um chefe ou alguém que exercia pressão, pelo contrário, era um mediador que estava ao lado dos cooperados e entendia tudo de reciclagem. Uma figura importante é a contadora Lourdes (também entrevistada) que estava lá pelo menos dois dias por semana para organizar toda a parte financeira, além de ajudar na resolução de conflitos. Os técnicos da SERP (Saúde Mental) e da Assistência Social também frequentavam a cooperativa para acompanhar semanalmente os usuários que eram responsáveis.

Conforme o diário de campo da pesquisa, a atividade central da cooperativa (reciclagem) acontecia da seguinte maneira:

Primeiro chegam os caminhões que pegam os materiais reciclados nas ruas de Santos, ou seja, a matéria-prima. Esta é despejada em um local próximo da esteira (máquina que faz com que os materiais deslizem por vários metros e terminem em outro ponto de descarte). Alguns cooperados colocam, com uma enxada, estes materiais na esteira para que os demais, colocados dos dois lados desta máquina, possam fazer a triagem dos materiais em muitos montes específicos (um de plástico, outro de papelão, outro de vidro etc.). Este processo se chama separação. Por fim, pesso- 
as da $\mathrm{X}$ (cooperativa terceirizada), fazem a prensa dos materiais naquele mesmo local e mandam para a comercialização. O rejeito, aquilo que sobra e não é aproveitado, é jogado em um transbordo ali perto e depois enviado para o lixão que fica na área continental de Santos (Diário de Campo).

Ali não é um lugar calmo, porque tem movimento constante de caminhões, pessoas entrando e saindo o tempo todo. Durante o tempo da nossa pesquisa, duas grandes obras aconteceram: a de reparação do teto e a de extensão do barracão, paralisando muitas vezes o trabalho deles. Jorge reitera esta dinâmica, trazendo para o campo das relações intersubjetivas:

Um dia comum pra mim é quando tem bastante confusão! Quando não tem, eu fico com medo, tem alguma coisa errada (risos)! Eu costumo até brincar com o pessoal, que aqui parece cadeia, quando tá muito silêncio, alguma bomba tá pra estourar aí (risos)... Aí eu me preocupo! (Encarregado Jorge, 41 anos).
O local de maior concentração de trabalhadores é a esteira. Em volta desta, presenciávamos mais de quarenta pessoas trabalhando e conversando. Este é um momento importante para o desenvolvimento das relações de amizade e também dos conflitos. A esteira (concreta) segue um ritmo em que os cooperados conseguem ver e retirar o material que está passando em sua frente para colocar nos respectivos sacos. Caso esteja muito rápida, eles pedem para diminuir o ritmo. Isto faz com que não haja a pressão que estamos acostumados a ver no sistema capitalista, em que o lucro está acima da saúde mental dos trabalhadores. Além disto, durante o período de trabalho, eles têm duas pausas para lanchar (de manhã e de tarde) e uma para almoçar. A Figura 2 representa o trabalho na esteira e apresentamos, como Figura 3, a foto dos cooperados neste local.

É interessante notar que o Relatório Final da IV Conferência Nacional de Saúde Mental - Intersetorial traz um avanço que já acontece na cooperativa estudada, mas que não é comum nos serviços de Saúde Mental pelo país:

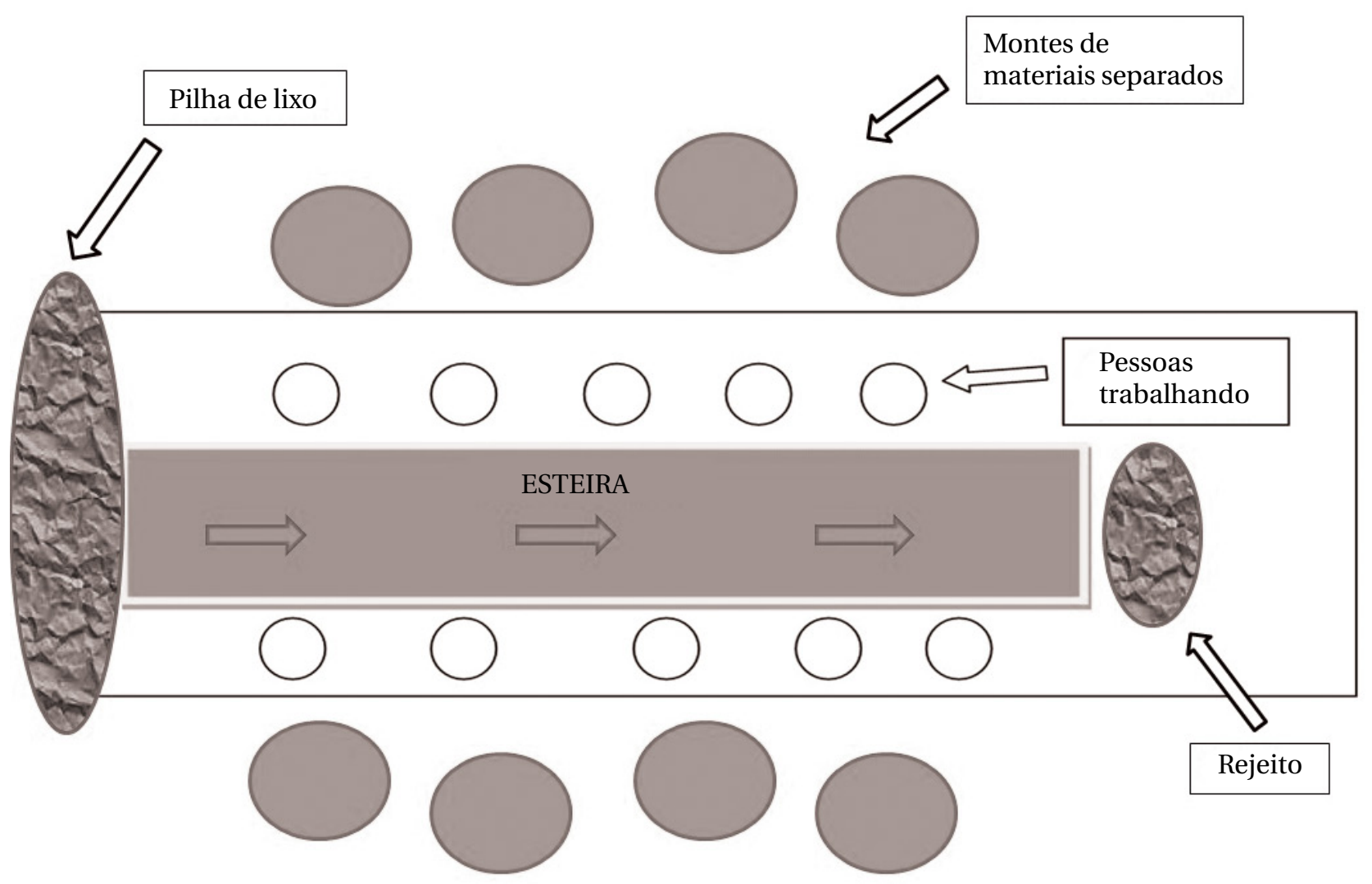

Figura 2

Esquema do local de maior concentração dos trabalhadores: a esteira. 
Regulamentar, na Política Nacional de Saúde Mental a implantação e consolidação dos projetos e oficinas de geração de trabalho e renda, priorizando a sua realização em sedes próprias, fora dos Centros de Atenção Psicossocial (CAPS), reafirmando que o espaço destinado ao acolhimento de pessoas com transtornos mentais e particularmente à crise (Centro de Atenção Psicossocial) deve ser distinto do espaço de trabalho (Brasil, 2010, p. 114).

Assim, a criação de centros de trabalho que não são dentro dos CAPS consolidaria um novo lugar social, que pudesse se descolar do estigma que os usuários dos serviços de saúde mental carregam. Com isso, o comprar por dó, por caridade, poderia ser substituído pelo comprar pelo belo trabalho desenvolvido e que me será útil. Para tanto, o relatório da IV Conferência propõe ações intersetoriais vinculadas, sobretudo, aos CRAS (Centros de Referência da Assistência Social), CAPS e NASF (Núcleos de Apoio à Saúde da Família). Assim, acreditamos que este caráter territorial e inter- setorial amplia as possibilidades dos usuários destes três serviços, que, muitas vezes, são as mesmas pessoas.

Neste contexto, vale dizer que a questão financeira é fundamental para compor a autonomia e a independência do usuário da Saúde Mental. Os projetos encabeçados pela SERP e que compõem a cooperativa estudada, seguem uma variação em relação à remuneração dos seus cooperados. A partir das entrevistas e das observações participantes, verificamos que os projetos das oficinas de geração de renda geravam apenas o valor dos produtos vendidos; o da cantina e das praças, um ganho de aproximadamente $\mathrm{R} \$ 300,00$ por mês; $\mathrm{e}$ o de reciclagem de lixo, curiosamente cobiçado pelos seus participantes, em torno de $\mathrm{R} \$ 700,00$ mensais. Próximo ao salário mínimo, este valor pareceu não ser ampliado pela repartição das sobras, comum na Economia Solidária e conhecida no sistema capitalista como divisão de lucros. O que observamos nas assembleias foi a discussão sobre benefícios para os cooperados, como vale-transporte, variações na alimentação cotidiana, cestas de Natal e viagem de fim de ano.

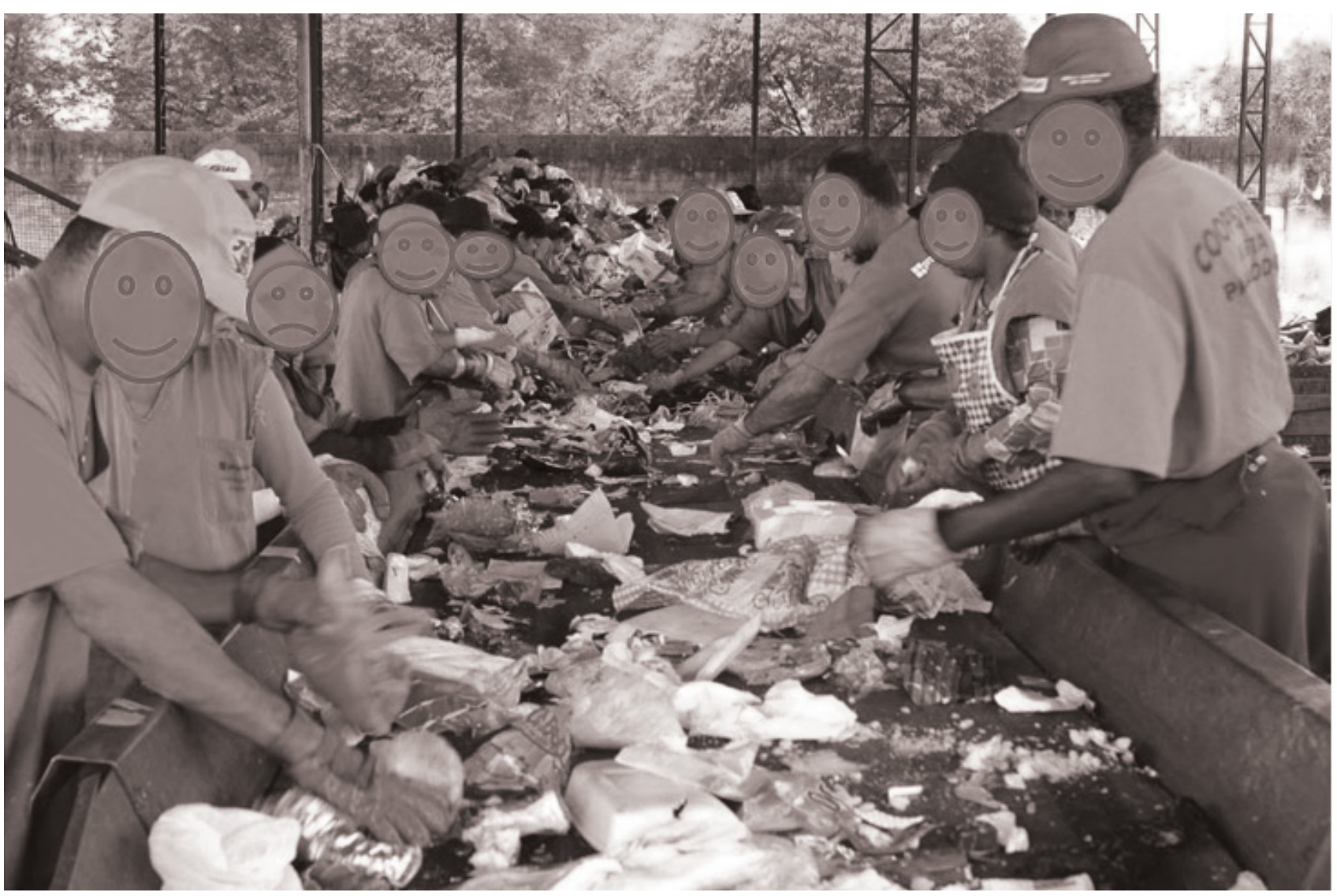

Figura 3

Foto do cotidiano dos cooperados em volta da esteira. 
Entender as formas de gestão e funcionamento da cooperativa é imprescindível para a compreensão dos processos de trabalho dos cooperados, porque permeiam o cotidiano. Acreditamos que em pesquisa qualitativa, estas questões sócio-históricas precisam ser estudadas, já que analisamos sentidos subjetivos em relação às materialidades que cercam as pessoas.

\section{Processos psicossociais e sentidos atribuídos pelos cooperados}

Nesta etapa de discussão trazemos a análise discursiva (Demo, 2012; Thompson, 2011), pela qual captamos o não dito, as entrelinhas e as contradições dos discursos, apreendendo o sentido da experiência e os desdobramentos para a vida das pessoas. Organizamos esta discussão em três núcleos: processos de gestão, sentidos atribuídos ao trabalho e a sociabilidade emergente.

\section{Processos de gestão}

Durante os meses de convivência na cooperativa, percebemos uma dinâmica que não estava escancarada, mas sim escondida, quieta, intocável. Uma dinâmica institucional que escondia seus poderes e seus mandões em sussurros e desvios de assunto. Começamos a problematizar esta questão nas entrevistas (nomes fictícios), como nos diálogos abaixo:

Entrevistador: Você acredita que é dono também da cooperativa?

Romário: (risos) Eu não sou dono de nada! (risos) Dono por que?! Eu não sou dono de nada! Eu só trabalho aqui!

Entrevistador: Mas pensando que você é um cooperado? Você sente que isso aqui também é seu?! Romário: Não, só trabalho aqui só, num sou. (risos) (Romário, 36 anos).

Entrevistador:Você se sente dona desta cooperativa? Mônica: Acho que dona não, tem dono né? Tem dono (risos). Não posso nem falar isso (risos).

Entrevistador: Quem é o dono?

Mônica: Não é o J.?

Entrevistador: Mas não são vocês?

Mônica: A gente se sente dono também né? Quer dizer, um pouco... às vezes, a pessoa, tipo assim, um colega joga um material errado, a gente se sente na obrigação de falar, na educação. Pra ajudar, né. Se a pessoa falar, eu até agradeço. Mas então, só se for nessa parte, né, que a gente, né? (Mônica, 54 anos).

Romário é categórico ao dizer que não é dono de nada, apenas trabalha ali. Já Mônica, apesar de responder que a cooperativa tem um dono, acaba percebendo que no cotidiano do trabalho, eles também desempenham este papel de zelar pela cooperativa e pelos seus colegas, avisando se eles fizerem algo de errado. Partindo da referência da Economia Solidária pela qual os cooperados administrariam horizontalmente e seriam donos do empreendimento, há uma contradição: as vozes dos trabalhadores e trabalhadoras somadas às nossas observações, evidenciam que eles não se consideram, de fato cooperados, tampouco donos da cooperativa. Eles sussurram, disfarçam, sorriem, mas deixam escapar que o dono é apenas uma pessoa e não o coletivo.

Um trecho de diário de campo soma-se a esta discussão:

Quando eu estava indo embora, três trabalhadores iniciaram um diálogo comigo: um usuário da Saúde Mental, o C. (um dos mais antigos ali) e outros dois da Assistência Social. O assunto girou em torno de uma necessidade de aumento de salário. Um destes últimos me disse que a cooperativa beneficiava os gestores, porque rende muito mais dinheiro do que eles ganham. Ele citou até valores (Diário de Campo).

No final da pesquisa, participamos de uma assembleia extraordinária em que não havia representantes (técnicos e gestores) de nenhuma das quatro instituições que participam da cooperativa - as secretarias municipais de Assistência Social, Meio Ambiente e Saúde (setor técnico da Saúde Mental) e a empresa mista. Isto evidencia que níveis hierárquicos de poder e decisão circulam naquele empreendimento, deixando para os cooperados, apenas espaços pseudodemocráticos de administração. É como se no andar de baixo se decidissem questões cotidianas e no andar de cima, negociações, parcerias, salários e o que fazer com as sobras. É necessário que as assembleias sejam espaços de autoridade maior (Singer, 2002) e que, neste caso, reúnam todas as partes envolvidas. Desta forma, haveria uma reinvenção de espaços de discussão democráticos produtores de 
autonomia e cidadania por meio da participação ativa dos seus trabalhadores, resgatando o teor ético-político presente no nascimento da cooperativa.

Para que haja uma transformação consistente, duradoura, é necessário não cair na ideia de doença como projeto (Carreteiro, 2011), em que o usuário da Saúde Mental ingressaria em um projeto de trabalho que predomine a heteronomia e a desvalorização do sujeito, criando a ilusão de incluí-lo socialmente - são os chamados projetos-doença. Como contraponto, a Reabilitação Psicossocial pela lógica da Economia Solidária e o fortalecimento de seus princípios é o que traz força para que as instituições não preguem a armadilha do projeto-doença. O direito de expressar sua opinião, a consciência dos processos de trabalho e as decisões coletivas integram a melhor maneira de mudar este jogo, possibilitam virar do avesso a história do trabalho na Psiquiatria. Os sujeitos desta pesquisa que antigamente seriam tratados como alienados “(...) num completo estado de minoridade social” (Castel, 1978, p. 55) começam a escrever uma nova história nos muros da Psiquiatria e transformar os murmúrios cruéis da sociedade em relação à loucura, em novas configurações de se lidar com ela.

Um contraponto neste assunto vem pelo discurso da contadora Lourdes, que enfatiza sua preocupação em dizer que eles são os verdadeiros donos do empreendimento:

Eles me veem ah... "é a dona Lourdes né? Eu acho que é a dona da cooperativa!” E eu friso muito que eu não sou dona! Que quem são donos são eles! Eu só sou empregada deles! Falo isso bem claro, deixo isso muito bem claro (...) E é isso que eu tento colocar né... todos os dias pra eles né? (Técnica Lourdes, 52 anos).

Por que se torna necessário resgatar esta questão todos os dias? Nesta dialética entre ser dono ou não, o cooperado Gustavo traz uma reflexão sobre o processo de trabalho neste local: "Aí qualquer coisa a gente vai ter que fazer uma reunião, aí eu falo: Oh! Num dá mais pra ela ficar não! Já arruma outra pessoa pra assumir a cooperativa, porque assim não dá!" (Gustavo, 33 anos).

Em uma empresa capitalista normalmente se aplica a heterogestão, ou seja, uma administração hierárquica, com diversos níveis de autoridade (Singer, 2002), sendo inviável um trabalhador pensar em convocar uma reunião para dizer que é preciso mudar a gestão. Durante a pesquisa, não observamos mudanças sólidas na gestão, porém verificamos que Gustavo sente que trabalha em um local em que sua voz é valorizada e reconhecida. Deste modo, entendemos que há possibilidades de autogestão, ou seja, uma administração democrática, que valoriza proporcionar o desenvolvimento humano aos seus praticantes, já que “(...) participar das discussões e decisões do coletivo, ao qual se está associado, educa e conscientiza, tornando a pessoa mais realizada, autoconfiante e segura" (Singer, 2002, p. 21).

Este potencial de mudança pode gerar o que Lane (2004) tratou como a questão alienação - consciência. A reflexão sobre as contradições e as consequências do modo de gerir a cooperativa e a possível ação de convocar uma reunião, seria um avanço no processo de conscientização. Se não houvesse reflexão, uma resposta pronta viria, como "é assim mesmo", o que seria reproduzir a ideologia de um grupo alienado.

Porém se a contradição é enfrentada, é analisada criticamente e é questionada no confronto com a realidade, o processo tem continuidade, onde cada ação é renovada e repensada, ampliando o âmbito de análise e da própria ação, e tem como consequência a conscientização do indivíduo (Lane, 2004, p. 43-44).

Nesta mesma linha de reflexão e consciência, o cooperado Caio diz em sua entrevista que reciclar é futuro! Gaiger (2009) afirma que o empreendimento econômico solidário, além de suprir as necessidades materiais dos cooperados, traz para si questões “[...] como reconhecimento, inserção social, autonomia, etc. Ao fazê-lo, introduzem, na esfera econômica, questões de fundo ético, que passam a incidir sobre aquele universo, mediante princípios normativos irredutíveis à lógica instrumental e utilitária" (Gaiger, 2009, p. 184).

Ainda que com todas as contradições presentes entre ser ou não dono, sentir-se com voz ou não e ter espaços pseudodemocráticos de decisão, estes processos de gestão solidária se direcionam para potenciais de produção de autonomia e cidadania que a inclusão pela Economia Solidária pode gerar para os usuários dos serviços de saúde mental. 


\section{Sentidos atribuídos ao trabalho}

Em entrevista cedida para esta pesquisa, a cooperada Maria contou uma história pessoal sofrida, dizendo que não tinha sentido na vida. Relatava muita instabilidade nos seus empregos como faxineira, manicure, servente, em restaurante, em salão de beleza, loja de presentes, discografia etc. Ela dizia que não tinha a cabeça boa na época, mas também deixou escapar que seus patrões eram rígidos e desrespeitosos. Desta maneira, entrar na cooperativa fez tudo mudar:

Hoje... é que hoje, a minha vida começou a mudar de seis anos pra cá. (...) Aonde eu morava, no J. C. (Rua), era assim! Eu, eu num tinha nem liberdade de fazer uma vitamina, porque já tinha gente na minha porta! (...) Mas eu num tô ligando pro lugar ser mais pesado, eu tô ligando em viver! Sabe? Eu tô ligando em viver! (Maria, 55 anos).

Em meio a tantas dificuldades encontradas, há o impulso em querer viver, ela está ligando em viver! Esta frase trouxe consigo uma emoção intensa que se traduz na potência de ação que ela expressa. Sawaia (2011b, p. 115) afirma que "potencializar pressupõe o desenvolvimento de valores éticos na forma de sentimentos, desejo e necessidades, para superar o sofrimentoético-político". Esta vivência vai ao encontro com a nossa visão de mundo, da Psicologia Sócio-Histórica, que “(...) entende que por trás da desigualdade social há vida, há sofrimento, medo, humilhação, mas também há o mais extraordinário milagre humano: a vontade de ser feliz e de recomeçar ali onde qualquer esperança parece morta" (Sawaia, 2009, p. 365).

Agora, com o trabalho na cooperativa e sentindo-se valorizada, Maria tem dinheiro para alugar seu quarto, ligar sua televisão ou fazer sua vitamina:

Mas aqui me deu um tipo de vida, que eu trabalho! Eu tenho direito ao banco! Eu tenho direito a cartão de crédito, quando eu me sinto apertada eu tenho onde passar! Não passo fome! Entendeu? Não passo fome! (...) Me deram cheque! (Maria, 55 anos).

O sentido do trabalho associado ao ganho de dinheiro e crédito, tornou-se um dos temas mais relatados nas entrevistas. Além de Maria, Romário também enfatiza que o trabalho lhe possibilita ajudar sua mãe e superar o que os outros falam dele.
Pô, muito, muito... ajuda bastante! Eu adoro isso! Só ajudar a minha mãe é o importante! É o importante, meu. (...) Eu ficava meio triste, viu? Mas agora num tô nem ligando! O que a pessoa fala ou deixa de falar pra mim, eu não tô nem ligando. Esse trabalho tá me ajudando muito! Muda muito mesmo, graças a Deus! E eu agradeço muito por esse trabalho, mano!!! (Romário, 36 anos).

A questão financeira surgiu como central para os sujeitos, sendo fruto do trabalho desempenhado. Há, em alguns casos, alguém da família que recebe este dinheiro e devolve para o cooperado em forma de "presente", ou "só pra tomar um refrigerante". Muitos não se dão conta que podem ser arrimos de família. A partir destes casos, entendemos que este tema é preciso ser incluído nas discussões e na atuação das equipes de reabilitação psicossocial em Saúde Mental, sobretudo no trabalho com familiares. Abaixo segue o exemplo da fala da Simone:

Gosto!!! Me deu possibilidade! Eu tenho conta aberta, mas é minha tia que mexe, é minha tia que mexe. E ela me dá dinheiro, e ela compra as coisas pra mim, e eu tenho até poupança, eu fui abrir com ela. Agora, quanto eu tenho, eu não sei. Tudo que tem com o nome do Santander eu entrego pra ela, eu não abro. (...) $\mathrm{O}$ trabalho ajuda a comprar roupa no Natal. Se eu pedir uma calcinha, minha tia vai e compra, ela vai e compra (Simone, 51 anos).

Já o cooperado Caio, que já esteve internado em um conhecido hospital psiquiátrico do estado de São Paulo, sente os reflexos do trabalho como sinônimos de liberdade:

O melhor trabalho que eu já gostei até hoje foi esse aqui. Porque eu acho um negócio mais... mais acelerado, entendeu? Rapidinho. (...) Ajuda, né, meu? Compro minha roupa, meu relógio! (mostra seu relógio para nós) Tem calendário, tem luz, tem é... paguei quinze real nele. É que eu pintei ele. Aí eu compro minha calça... todo dia compro pão, compro salgado pra minha filha, né? Vou pro supermercado de bike! (Caio, 57 anos).

No modo de produção vigente, o capitalismo não se refere às reais necessidades das pessoas, mas o ato de ir às compras refere-se predomi- 
nantemente à superficialidade, à futilidade e ao modismo. Os cooperados acabam subvertendo esta lógica, produzindo novos sentidos para este ato de comprar: autonomia, cidadania, afeto, simplicidade e liberdade. Estas contradições que nascem junto com o capitalismo, encontram resistências na Economia Solidária.

Entendemos, portanto, que os sentidos em relação à cooperativa, são positivos. Outrora, quando conseguiam outros empregos, eram tratados como loucos, eram humilhados e pouco valorizados.

\section{A sociabilidade emergente}

Ainda não é possível falar em muitas amizades, famílias totalmente acolhedoras e uma sociedade que os aceita completamente - uma sociabilidade emergente (Kinker, 2011), mas que vem gerando satisfação e felicidade para os sujeitos da pesquisa, que anteriormente foram trancafiados em hospitais psiquiátricos e humilhados pela sociedade.

Simone que já esteve amarrada e sem comida, traz a experiência de passar pelo emblemático hospital Anchieta de Santos, Brasil:

Simone: Eu adoeci com 28 anos...

Entrevistador: Você conheceu o Anchieta?

Simone: Conheci, fiquei três semanas lá. Uma semana cada vez.

Entrevistador: Como era lá?

Simone: Uma loucura! A primeira vez que eu fui, eu tentei fugir, eles pegaram e me amarraram. Uma loucura... São totalmente loucos, totalmente sem sentido! Fazem as coisas sem sentido.

Entrevistador: As pessoas ou quem trabalhava também?

Simone: As enfermeiras gostavam de castigar, castigavam! Tinha outras que era mais humanas... Mas eles cagavam no corredor... se sujavam de cocô... comiam cocô... Fiquei sem comida e pedi pra me tirarem de lá (Simone, 51 anos).

Muitas pessoas passaram um longo período de suas vidas em um lugar como este. Simone, apesar de ter ficado três semanas, mostra o anseio de estar livre e construir esta sociabilidade:

Aí eu gosto de interagir! Eu gosto de cinema, teatro, vou pra Quinze (rua de barzinhos da cidade), passeio, caminho, vou na banca de jornal na rodoviária! Vou muito na rodoviária! Converso muito com o pessoal lá! (...) Aí eu fico interagindo ali, peço um cafezinho pras moças e elas me dão, às vezes, eu compro... De fim de semana eu vou de madrugada, mas durante a semana eu vou depois do serviço! Eu tenho psiquiatra pra ir, eu tenho que buscar remédio no AME, eu tenho que ir no INSS, eu tenho que buscar remédio no NAPS, eu tenho outros médicos... Tudo isso eu faço... Eu interajo com a sociedade! (Simone, 51 anos).

O trabalho é ontológico ao ser humano (Salgueiro, 2013) e quando faz sentido para a pessoa, produz sociabilidade e transformação social. Aloísio, há doze anos na cooperativa e Joaquim, um jovem de 23 anos, comentam sobre os resultados positivos que este trabalho vem gerando:

Eu vim trabalhar aqui e comecei a melhorar! Melhorando, melhorando e tô até hoje! Tô até hoje aqui, entendeu?! E esse período foi muito bom pra mim, porque eu acabei os estudo... né? Acabei o estudo... (Aloísio, 53 anos).

Aqui eu gosto das pessoas daqui pra caramba! (...) Se eu pudesse ser amigo de todo mundo aqui, eu seria! (...) Acabo dando risada com a brincadeira que os outros fazem! (...) Eu, quando entrei aqui, eu era quietão! Antigamente eu ficava na classe muda, 'Ai, esse menino não fala nada! Num sei o que!' Aí eu fui conversando, aí eu vi os outros brincando, aí eu comecei a conversar mais! (Joaquim, 23 anos).

Do ponto de vista psicossocial, este trabalho vem possibilitando a busca pela educação formal e a conquista de relações de amizade e afeto. Isto produz novas formas de sociabilidade que destroem barreiras, como a da dialética exclusão-inclusão dupla vivida pelos usuários dos serviços de saúde mental, porque, além viverem em situação de pobreza, são vistos e tratados como loucos.

\section{Conclusões}

Para finalizar, procuramos reconstruir a informação qualitativa de maneira criativa, sintética e 
crítica (Demo, 2012), trazendo a reinterpretação do que está pré-interpretado, a partir da relação entre as duas etapas anteriores (sócio-histórica e discursiva).

Constatamos neste estudo que a cooperativa em questão é um ícone na Reforma Psiquiátrica brasileira. Esta afirmação é embasada pelos seguintes motivos: é um marco histórico, pois nasce na intervenção do hospital Anchieta em Santos e se mantém por décadas; é uma das poucas cooperativas de Saúde Mental no país que reúne geração efetiva de renda para os trabalhadores, boa estrutura física e parcerias sólidas, além de possibilitar a inclusão social pelo trabalho para seus cooperados. Estes motivos são mais inspiradores quando percebemos no cotidiano que as relações intersubjetivas, despidas da competição que o sistema capitalista produz, refletem positivamente na vida destas pessoas.

Há, no entanto, contradições importantes neste contexto, como a questão da autonomia dos sujeitos dentro e fora da cooperativa. A Economia Solidária tem a autogestão como um dos seus princípios, mas pudemos verificar que são poucas e mínimas as decisões que os trabalhadores realmente tomam em assembleia. Com isto, eles não se sentem donos do empreendimento, tampouco aplicam uma pura autogestão dentro da cooperativa. Já fora dela, apesar das enormes conquistas do ponto de vista psicossocial, a renda que eles geram é muitas vezes manipulada pelas famílias. Até que ponto esse dinheiro preso pela família gera autonomia? Por que eles ainda são vistos como incapazes de manipular o dinheiro que é fruto do seu próprio trabalho? Estas reflexões atingem o seio do processo dialético de exclusão/inclusão social vivido pelos usuários dos serviços de Saúde Mental, porque se a família que assiste ao crescimento destas pessoas não acredita que elas são capazes de gerir seu próprio dinheiro, quem dirá a sociedade. Seria importante novos estudos que verifiquem se há uma manipulação destes familiares para ficarem com o dinheiro para eles, uma questão perversa e despotencializadora do ponto de vista da autonomia e da ética.

Observamos in loco que deve haver na prática da reabilitação psicossocial esta preocupação em criar espaços de negociação entre sociedade, família e loucura (Saraceno, 1999) e em produzir vida (Nicácio, \& Kinker, 1997), questões que são ontologicamente construídas na relação com o outro (Sawaia, 2009), nas relações intersubjetivas.

Com muitas reflexões a se fazer e muito trabalho a se concretizar no campo da reabilitação psicossocial, compreendemos que a Saúde Mental aliada à Economia Solidária em Santos, assumiu sua parceria com as leis de incentivo, instituições públicas e privadas, o que vem sustentando este projeto. Pela nossa experiência (baseada em pesquisas acadêmicas, práticas institucionais e acompanhamento dos empreendimentos da Rede de Saúde Mental e Economia Solidária - Saúde EcoSol), muitos projetos destes se iniciam e perdem o fôlego por não firmarem estas relações institucionais e políticas. Portanto, entendemos esta necessidade de se seguir algumas lógicas do mercado, sem perder de vista os princípios da Economia Solidária que pretendem entrar no seio do capitalismo e combater sua perversão. Seria apenas uma roupagem para atingir seus objetivos.

Concluímos que a cooperativa estudada: efetivamente gera renda e subversão à lógica do consumismo, pois seus cooperados enfatizam temas como não passar fome, ajudar a família e poder frequentar espaços sociais sem o sentimento de humilhação; produz estabilidade, porque muitos estão na cooperativa há mais de três anos e alguns há mais de dez; os sentidos deste trabalho são mostrados pelos afetos de felicidade, reconhecimento e carinho e há cooperação em detrimento da competição no ambiente de trabalho, o que gera tranquilidade, segurança, menos pressão e mais saúde mental.

Consideramos por fim que os projetos de inclusão social pelo trabalho da Saúde Mental, precisam de fato assumir a Economia Solidária. Esta posição trará a força de uma ideologia que não compactua com os diversos modos de sofrimento que o capitalismo impõe. Para isso, é necessário estimular a autogestão, aliada à participação social de seus trabalhadores, por meio do desenvolvimento de assembleias como instrumento maior de decisão entre todas as partes interessadas, além do fortalecimento de uma cultura solidária com a formação em cooperativismo e Economia Solidária. Isto possivelmente irá desenvolver a cidadania e gerar formas de enfrentamento ao capitalismo e aos processos dialéticos de inclusão/exclusão que este impõe. 


\section{Referências}

Aguiar, W. M. J., \& Ozella, S. (2006). Núcleos de significação como instrumento para a apreensão da constituição dos sentidos. Psicologia: Ciência $e$ Profissão, 26(2), 222-245. Recuperado de http:// pepsic.bvsalud.org/scielo.php?script=sci_arttext\&pid=S1414-98932006000200006\&lng=es\&nrm $=$ is\&tlng=pt

Aguiar, W. M. J., \& Ozella, S. (2013). Apreensão dos sentidos: aprimorando a proposta dos núcleos de significação. Revista Brasileira de Estudos Pedagógicos, 94(236), 299-322. doi:10.1590/S2176-66812013000100015

Andrade, M. C., Burali, M. A. M., Vida, A., Fransozio, M. B. B., \& Santos, R. Z. (2003). Loucura e trabalho no encontro entre Saúde Mental e economia solidária. Psicologia: Ciência e Profissão, 33(1), 174-191. doi:10.1590/S1414-98932013000100014

Bonadio, A. N., \& Silveira, C. (2013). Economia solidária e reabilitação vocacional no campo da drogadição: possibilidades e limites das práticas atuais. Saúde e Sociedade, São Paulo, 22(1), 99-108. doi:10.1590/S0104-12902013000100010

Brasil. (1990). Lei No 8.080, de 19 de setembro de 1990. Dispõe sobre as condições para a promoção, proteção e recuperação da saúde, a organização e o funcionamento dos serviços correspondentes e dá outras providências. Diário Oficial da União. 20 de setembro de 1990.

Brasil. (2002). Ministério da Saúde. Portaria/GM No 336, de 19 de fevereiro de 2002. [Estabelece que os Centros de Atenção Psicossocial poderão constituir-se nas seguintes modalidades de serviço: CPAS 1, CAPS 11 e CAPS 111].

Brasil. (2010). Sistema Único de Saúde. Conselho Nacional de Saúde. Comissão Organizadora da IV Conferência Nacional de Saúde Mental - Intersetorial. Relatório final da IV Conferência Nacional de Saúde Mental -Intersetoria. Brasília, DF: Conselho Nacional de Saúde.

Carreteiro, T. C. (2011). A doença como projeto: uma contribuição à análise de formas de afiliações e desafiliações sociais. In B. B. Sawaia (Org.). As artimanhas da exclusão: análise psicossocial e ética da desigualdade social. (11a ed., pp. 89-97). Petrópolis, RJ: Vozes.

Castel, R. (1978). A ordem psiquiátrica: a idade de ouro do alienismo (M. T. C. Albuquerque, trad.). Rio de Janeiro, RJ: Graal.
Demo, P. (2012). Pesquisa e informação qualitativa: aportes metodológicos (5a ed.). Campinas, SP: Papirus. Gaiger, L. I. (2009). Empreendimento econômico solidário. In A. D. Catani, J. L. Laville, L. I. Gaiger, \& P. Hespanha, Dicionário internacional da outra economia. São Paulo, SP: Almedina Brasil.

Gaiger, L. I. (2013). A economia solidária e a revitalização do paradigma cooperativo. Revista Brasileira de Ciências Sociais, 28(82), 211-229. doi:10.1590/S0102-69092013000200013

González-Rey, F. L. (2011). Pesquisa qualitativa em psicologia: caminhos e desafios (M. A. F. Silva, trad.; F. L. González Rey, rev. tecn.). São Paulo, SP: Cengage Learning.

Heller, A. (2008). O cotidiano e a história (C. N. Coutinho, \& L. Valentini, trads.). São Paulo, SP: Paz e Terra.

Kinker, F. S. (2011). Fragmentos de uma sociabilidade emergente: a trajetória do Núcleo de Trabalho do Programa de Saúde Mental de Santos (1989-1996) (tese de doutorado). Pontifícia Universidade Católica de São Paulo, São Paulo.

Kinoshita, R. T. (2009). Saúde mental e a antipsiquiatria em Santos: vinte anos depois. Cadernos Brasileiros de Saúde Mental, 1(1). Recuperado de http:// incubadora.periodicos.ufsc.br/index.php/cbsm/ article/view/ 1017

Lane, S. (2004). Consciência/alienação: a ideologia no nível individual. In S. Lane, \& W. Codo (Orgs). Psicologia social: o homem em movimento. São Paulo, SP: Brasiliense.

Martins, S. T. F. (2003). Processo grupal e a questão do poder em Martín-Baró. Psicologia \& Sociedade, 15(1),201-217.doi:10.1590/S0102-71822003000100011

Minayo, M. C. S. (2010). O desafio do conhecimento: pesquisa qualitativa em saúde (12a ed.). São Paulo, SP: Hucitec.

Nicácio, F., \& Kinker, F. S. (1997). O desafio de viver fora: construindo a Cooperativa Paratodos. In: F. C. B. Campos, \& C. M. P. Henriques (Org.), Contra a maréà beira mar: a experiência do SUS em Santos (2a ed. rev. e amp.; pp. 167-177). São Paulo, SP: Hucitec.

Nicácio, F. N., Mangia, E. F., \& Ghirardi, M. I. G. (2005). Projetos de inclusão no trabalho e emancipação de pessoas em situação de desvantagem: uma discussão de perspectivas. Revista de Terapia Ocupacional da Universidade de São Paulo, 16(2), 62-66. doi:10.11606/issn.2238-6149.v16i2p62-66 
Salgueiro, J. E. (2013). O trabalho e o trabalhador na dramaturgia de Plínio Marcos: dois perdidos numa noite suja (tese de doutorado). Pontifícia Universidade Católica de São Paulo, São Paulo.

Saraceno, B. (1999). Libertando identidades: da reabilitação psicossocial à cidadania possível. (L. H. Zanetta, M. C. Zanetta, \& W. Valentini, trads.). Belo Horizonte, MG: Te Corá.

Sato, L., \& Souza, M. P. R. (2001). Contribuindo para desvelar a complexidade do cotidiano através da pesquisa etnográfica em psicologia. Psicologia USP, 12(2),29-47. doi:10.1590/S0103-65642001000200003

Sawaia, B. B. (2011a). Introdução: exclusão ou inclusão perversa? In B. B. Sawaia (Org.), As artimanhas da exclusão: análise psicossocial e ética da desigualdade social (11a ed.; pp. 7-13). Petrópolis, RJ: Vozes.

Sawaia, B. B. (2011b). O sofrimento ético-político como categoria de análise da dialética exclusão/inclusão. In B. B. Sawaia (Org.). As artimanhas da exclusão: análise psicossocial e ética da desigualdade social (11a ed.; pp. 99-119). Petrópolis, RJ: Vozes.

Sawaia, B. B. (2009). Psicologia e desigualdade social: uma reflexão sobre liberdade e transformação social. Psicologia \& Sociedade, 21(3), 364-372. doi:10.1590/S0102-71822009000300010

Singer, P. (2002). Introdução à economia solidária. São Paulo, SP: Fundação Perseu Abramo.

Thompson, J. B. (2011). Ideologia e cultura moderna: teoria social crítica na era dos meios de comunicação de massa (9a ed., Grupo de Estudos sobre Ideologia, comunicação e representações sociais da pós-graduação do Instituto de Psicologia da PUCRS, trad.). Petrópolis, RJ: Vozes.
Ramiz Candeloro Pedroso de Moraes

Docente do Centro Universitário UNIFAFIBE. Bebedouro - SP. Brasil.

E-mail: ramizcpm@hotmail.com

Carlos Roberto de Castro-Silva

Docente da Universidade Federal de São Paulo UNIFESP, São Paulo - SP. Brasil.

E-mail: carobert3@hotmail.com

Endereço para envio de correspondência Centro Universitário UNIFAFIBE, Curso de Psicologia. Rua Prof. Orlando França de Carvalho, 325 - Centro, Bebedouro - SP, CEP: 14701-070.

Recebido 29/07/2015

Reformulação 23/12/2015

Aprovado 19/07/2016

Received 07/29/2015

Reformulated 12/23/2015

Approved 07/19/2016

Recibido 29/07/2015

Reformulado 23/12/2015

Aceptado 19/07/2016

Como citar: Moraes, R. C. P., \& Castro-Silva, C. R. (2016). Sentidos e processos psicossociais envolvidos na inclusão pelo trabalho na Saúde Mental. Psicologia: Ciência e Profissão, 36(3): 748-762. doi:10.1590/ 1982-3703002372015

How to cite: Moraes, R. C. P., \& Castro-Silva, C. R. (2016). Senses and psychosocial processes involved in the work of social inclusion in Mental Health. Psicologia: Ciência e Profissão, 36(3): 748-762. doi:10.1590/1982-3703002372015

Cómo citar: Moraes, R. C. P., \& Castro-Silva, C. R. (2016). Sentidos y procesos psicosociales involucrado en inclusión a través de trabajo en Salud Mental. Psicologia: Ciência e Profissão, 36(3): 748-762. doi:10.1590/1982-3703002372015 